\title{
SELF EFFICACY PEREMPUAN USIA 35-44 TAHUN DALAM UPAYA PENCEGAHAN KANKER PAYUDARA
}

\author{
SELF EFFICACY OF WOMAN AGED 35-44 YEARS IN BREAST CANCER \\ PREVENTION EFFORT
}

\author{
Windi Susilowati, M. Bagus Qomaruddin \\ Departemen Promosi Kesehatan dan Ilmu Perilaku, \\ Fakultas Kesehatan Masyarakat, Universitas Airlangga, Surabaya \\ Email: windi.susilowati.ws@gmail.com
}

\begin{abstract}
Based on data from Health Department of Surabaya on Reports Puskesmas in Surabaya at 2015 discovered that the number of breast cancer patients over the years also increased. More than $30 \%$ of cancer can be prevented with breast self examination (BSE). Puskesmas with BSE declining coverage in a row is a big health center coverage is Puskesmas Tembok Dukuh with 1.89\% in 2014 and then declined in 2015 to $1.22 \%$. This study used observational research and cross sectional design. Researchers took samples with simple random sampling with 33 respondents. Independent variables in this study is performance accomplishment, vicarious experience, social persuasion dan physiological and emotional states. And the dependent variables in this study is self efficacy and BSE. Data analysis using cross tabulations. And the result that good performance accomplishment, vicarious experience, social persuasion dan physiological and emotional states it will have an impact on his self efficacy. The conclusion of this study is the majority of respondents with good self efficacy have a good BSE. Therefore it is necessary to increase the numbers of BSE coverage by increasing self efficacy by providing values of motivation to be concerned about her reproductive health.
\end{abstract}

Keywords: Behavior, BSE, Social Cognitive Theory

\begin{abstract}
Abstrak: Berdasarkan data dari Dinas Kesehatan Kota Surabaya tentang laporan Puskesmas di Kota Surabaya tahun 2015 diketahui bahwa jumlah penderita kanker payudara dari tahun ke tahun juga mengalami peningkatan. Lebih dari $30 \%$ penyakit kanker dapat dicegah melalui periksa payudara sendiri (SADARI). Puskesmas dengan cakupan SADARI yang mengalami penurunan berturut-turut adalah Puskesmas Tembok Dukuh dengan besar cakupan 1,89\% pada tahun 2014 kemudian menurun pada tahun 2015 menjadi 1,22\%. Penelitian ini menggunakan jenis penelitian observasional dengan menggunakan desain penelitian Cross Sectional. Teknik penelitian yang digunakan adalah Simple Random Sampling sebanyak 33 responden. Variabel Independen dalam penelitian ini adalah performance accomplishment, vicarious experience, social persuasion dan physiological and emotional states. Variabel dependen dalam penelitian ini adalah self efficacy dan perilaku periksa payudara sendiri. Analisis data menggunakan tabulasi silang. Dan diperoleh hasil bahwa performance accomplishment, vicarious experience, social persuasion dan physiological and emotional states yang baik maka akan memberikan dampak bagi self efficacy seseorang. Kesimpulan yang didapat dari penelitian ini adalah mayoritas responden dengan self efficacy baik memiliki perilaku SADARI yang baik pula. Oleh sebab itu perlu dilakukan peningkatan angka cakupan SADARI dengan meningkatkan self efficacy dengan memberikan nilai-nilai motivasi agar lebih peduli terhadap kesehatan reproduksi nya.
\end{abstract}

Kata kunci: Perilaku, SADARI, Teori Kognitif Sosial

\section{PENDAHULUAN}

Kanker adalah penyakit tidak menular yang ditandai dengan pertumbuhan sel tidak normal atau terus-menerus dan tidak terkendali yang dapat merusak jaringan sekitarnya serta dapat menjalar ke tempat yang jauh dari asalnya yang disebut dengan metastasis. Sel kanker bersifat ganas dapat berasal atau tumbuh dari setiap jenis sel di tubuh manusia (Depkes RI, 2009). Sekitar 7,5 juta orang diperkirakan meninggal akibat penyakit kanker. Kanker merupakan penyebab kematian nomer 2 di dunia setelah penyakit kardiovaskuler. Lebih dari $70 \%$ kematian terjadi pada negara berkembang dan negara miskin. Sedangkan untuk jenis kanker tertinggi pada perempuan di dunia adalah penyakit kanker payudara dan kanker 
leher rahim (WHO, 2013). Keganasan pada jaringan payudara yang berasal dari epitel duktus maupun lobulusnya dapat mengakibatkan kanker payudara. Data dari Pathological Based Registration di Indonesia menyatakan bahwa kanker payudara menempati urutan pertama dengan frekuensi kejadian relatif sebesar 18,6\% (Data Kanker Indonesia, 2010). Insiden kanker meningkat secara drastis dari 12,7 juta kasus pada tahun 2008 menjadi 14,1 juta kasus pada tahun 2012, dengan jumlah kematian meningkat dari 7,6 juta orang tahun 2008 menjadi 8,2 juta pada tahun 2012 (WHO, 2013).

Data dari Globocan/IARC menyebutkan bahwa pada tahun 2012 kanker payudara merupakan penyakit kanker dengan persentase kasus baru tertinggi, yaitu sebesar $43,3 \%$, dengan persentase kematian sebesar $12,9 \%$. Provinsi Jawa Timur dan Jawa Tengah merupakan 2 provinsi dengan jumlah penderita kanker payudara terbesar di Indonesia. Provinsi Jawa timur memiliki jumlah penderita kanker payudara sebanyak 9.688 orang sampai dengan tahun 2013, diikuti oleh Provinsi Jawa Tengah yang memiliki jumlah penderita kanker payudara sebanyak 6.701 orang (Riskesdas, 2013).

Berdasarkan data dari Dinas Kesehatan Kota Surabaya tentang laporan Puskesmas di Kota Surabaya tahun 2015 diketahui bahwa jumlah penderita kanker payudara dari tahun ke tahun juga mengalami peningkatan. Pada tahun 2013 jumlah penderita kanker payudara sebanyak 42 orang, kemudian meningkat sampai dengan tahun 2015 mencapai hingga 204 orang (Dinkes Kota Surabaya, 2015).

Tingginya jumlah kasus baru pada penyakit kanker payudara tentu perlu mendapat perhatian khusus bagi Tenaga Kesehatan dan Institusi terkait, mengingat lebih dari 30\% penyakit kanker dapat dicegah dengan cara mengubah faktor risiko perilaku, pola makan penyebab penyakit kanker, dan deteksi dini. Penyakit kanker yang diketahui sejak dini memiliki kemungkinan untuk mendapatkan penanganan yang lebih optimal. Kegiatan deteksi dini kanker payudara dilakukan dengan mengajarkan Periksa Payudara Sendiri (SADARI). Pemeriksaan SADARI memiliki tujuan guna menemukan benjolan tidak normal pada payudara sedini mungkin agar dapat dilakukan tindakan deteksi dini. Berdasarkan data Subdit Kanker Direktorat Pengendalian Penyakit Tidak Menular (PPTM) Kemenkes RI, jumlah perempuan seluruh Indonesia umur 30-50 tahun adalah 36.761.000. Sejak tahun 2007 hingga tahun 2013 deteksi dini yang telah dilakukan oleh perempuan sebanyak 644.951 orang $(1,75 \%)$ dengan penemuan suspek benjolan (tumor) payudara 1.682 orang (2,6 per 1000 penduduk) (Kemenkes RI, 2014).

Tahun 2013 program deteksi dini kanker payudara terselenggara pada 717 Puskesmas dari total 9.422 Puskesmas yang berada di 304 Kabupaten/Kota di 34 Provinsi di Indonesia. Dari 717 Puskesmas tersebut didapatkan cakupan deteksi dini kanker payudara sebesar 7,6\%. Selanjutnya pada tahun 2014 program deteksi dini kanker payudara ini diselenggarakan pada 1.986 Puskesmas dengan cakupan deteksi dini kanker payudara sebesar $2,45 \%$. Meningkatnya jumlah kepesertaan Puskesmas yang mengikuti program ini tidak diikuti oleh kenaikan jumlah cakupan deteksi dini kanker payudara. Hal ini menimbulkan berbagai pertanyaan sehingga memerlukan upaya lebih kuat untuk mencapai target dengan melakukan deteksi dini terhadap perempuan (Kemenkes RI, 2014).

Tahun 2015 dalam laporan tahunan didapatkan hasil bahwa penyakit kanker yang tertinggi adalah kanker payudara yaitu sebesar 204 penderita dan diikuti oleh penyakit kanker leher rahim yaitu sebesar 60 penderita. Sebanyak 204 penderita kanker payudara tersebar dalam 58 Puskesmas. Puskesmas dengan cakupan SADARI yang mengalami penurunan berturutturut adalah Puskesmas Tembok Dukuh dengan besar cakupan $1,89 \%$ pada tahun 2014 kemudian menurun pada tahun 2015 menjadi 1,22\% (Dinkes Kota Surabaya, 2015). Data pada Puskesmas Tembok Dukuh menyebutkan bahwa penyakit kanker payudara paling banyak diderita oleh perempuan yang berusia produktif, yaitu berada pada kisaran usia 35-44 tahun. Banyaknya jumlah penderita kanker di usia tersebut tentu akan memberikan dampak 
bagi kehidupannya, mengingat pada usia tersebut masih tergolong dalam usia produktif. Oleh karena itu perlu dilakukan upaya pencegahan untuk meningkatkan kesadaran masyarakat khususnya perempuan dalam mengenali gejala dan risiko penyakit kanker sehingga dapat menentukan langkahlangkah pencegahan dan deteksi dini yang tepat. Dalam upaya pencegahan kanker payudara dapat dilakukan dengan melakukan SADARI. SADARI dinilai sebagai suatu upaya pencegahan yang cukup efektif, karena dapat dilakukan secara mandiri dan tanpa memerlukan biaya. Dalam melakukan SADARI dibutuhkan suatu komitmen untuk melaksanakannya dan perlu suatu keyakinan diri (self efficacy) agar SADARI dapat dilakukan secara rutin setiap bulan.

Penelitian ini memiliki tujuan untuk menganalisis faktor-faktor yang berkorelasi dengan self efficacy perempuan dalam melakukan SADARI berdasarkan teori kognitif sosial. Dengan cara menganalisis korelasi performance accomplishments dengan self efficacy perempuan usia 35-44 tahun dalam melakukan SADARI, menganalisis korelasi vicarious experience dengan self efficacy perempuan usia 35-44 tahun dalam melakukan SADARI, menganalisis korelasi social persuasion dengan self efficacy perempuan usia 35-44 tahun dalam melakukan SADARI dan menganalisis korelasi physiological and emotional states dengan self efficacy perempuan usia 35-44 tahun dalam melakukan SADARI.

\section{METODE}

Penelitian ini menggunakan jenis penelitian observasional, dengan menggunakan desain penelitian Cross Sectional. Sampel yang digunakan pada penelitian ini ditentukan dengan teknik simple random sampling, yaitu sebesar 33 responden yang merupakan perempuan usia 35-44 tahun yang mengikuti program deteksi dini kanker payudara di wilayah kerja Puskesmas Tembok Dukuh Kota Surabaya. Pengambilan data dilakukan pada bulan November 2016 sampai dengan bulan Desember 2016. Tempat pengambilan data di Puskesmas Tembok Dukuh Kota
Surabaya. Teknik pengumpulan data diambil dan dikumpulkan dari data primer dan sekunder. Data primer diambil dengan cara menggunakan instrumen kuesioner. Hasil wawancara yang dilakukan kepada responden dan tenaga kesehatan pemegang Program Kesehatan Reproduksi Puskesmas Tembok Dukuh, serta observasi yang dilakukan oleh peneliti saat pelayanan Poli Kesehatan Reproduksi sedang berlangsung. Untuk data sekunder diperoleh dari Puskesmas Tembok Dukuh Kota Surabaya.

Lembar kuesioner yang sudah diisi oleh responden kemudian diolah dengan teknik editing, coding, dan skoring. Data yang sudah diolah tersebut kemudian di analisis untuk melihat faktor-faktor yang berhubungan dengan self efficacy perempuan usia 35-44 tahun dalam melakukan SADARI dengan menggunakan tabulasi silang. Kemudian dari data yang sudah dianalisis tersebut kemudian dikategorikan dalam self efficacy rendah, self efficacy sedang atau self efficacy baik. Analisis data yang digunakan adalah crosstabs (tab. silang).

\section{HASIL PENELITIAN}

Hasil pengambilan data pada penelitian yang dilakukan didapatkan hasil distribusi frekuensi responden berdasarkan karakteristik dari Performance Accomplishment, Vicarious Experience, Social Persuasion, Physiological and Emotional State dan Self Efficacy.

Adapun masing-masing variabel tersebut memiliki sub variabel tersendiri, seperti pada Performance Accomplishment terdiri dari pengetahuan, pengalaman masa lalu dan kemampuan bertindak. Pada Vicarious Experience terdiri dari pengalaman keluarga dan pengalaman orang terdekat. Pada Social Persuasion terdiri dari dukungan sosial dan informasi kesehatan. Pada Physiological and Emotional State terdiri dari penghasilan keluarga, suasana hati dan perasaan emosi yang negatif.

Hasil penelitian menurut variabel Performance Accomplishment dapat dilihat pada tabel 1.

Tabel 1 menunjukkan jumlah terbanyak adalah responden dengan pengetahuan cukup yang memiliki self efficacy baik yaitu 
Tabel 1. Distribusi Frekuensi Berdasarkan Performance Accomplishment dan Self Efficacy

\begin{tabular}{|c|c|c|c|c|c|}
\hline \multicolumn{6}{|c|}{ Performance Accomplishment } \\
\hline \multirow{3}{*}{$\begin{array}{c}\text { Tingkat } \\
\text { Pengetahuan }\end{array}$} & \multicolumn{4}{|c|}{ Self Efficacy } & \multirow{2}{*}{$\sum$} \\
\hline & \multicolumn{2}{|c|}{ Sedang } & \multicolumn{2}{|c|}{ Baik } & \\
\hline & $\mathbf{n}$ & $\%$ & $\mathbf{n}$ & $\%$ & $\mathbf{N}$ \\
\hline Kurang & 1 & 50 & 1 & 50 & 2 \\
\hline Cukup & 7 & 26,9 & 19 & 73,1 & 26 \\
\hline Baik & 0 & 0 & 5 & 100 & 5 \\
\hline Total & 8 & 24,2 & 25 & 75,8 & 33 \\
\hline \multirow{3}{*}{$\begin{array}{c}\text { Pengalaman Masa } \\
\text { Lalu }\end{array}$} & \multicolumn{4}{|c|}{ Self Efficacy } & $\Gamma$ \\
\hline & \multicolumn{2}{|c|}{ Sedang } & \multicolumn{2}{|c|}{ Baik } & 2 \\
\hline & $\mathbf{n}$ & $\%$ & $\mathbf{n}$ & $\%$ & $\mathbf{N}$ \\
\hline Risiko Rendah & 5 & 21,7 & 18 & 78,3 & 23 \\
\hline Risiko Tinggi & 3 & 30 & 7 & 70 & 10 \\
\hline Total & 8 & 24,2 & 25 & 75,8 & 33 \\
\hline \multirow{3}{*}{$\begin{array}{c}\text { Kemampuan } \\
\text { Bertindak (skill) }\end{array}$} & \multicolumn{4}{|c|}{ Self Efficacy } & $\Gamma$ \\
\hline & \multicolumn{2}{|c|}{ Sedang } & \multicolumn{2}{|c|}{ Baik } & 之 \\
\hline & $\mathbf{n}$ & $\%$ & n & $\%$ & $\mathbf{N}$ \\
\hline Skill Kurang & 3 & 100 & 0 & 0 & 3 \\
\hline Skill Baik & 5 & 16,7 & 25 & 83,3 & 30 \\
\hline Total & 8 & 24,2 & 25 & 75,8 & 33 \\
\hline
\end{tabular}

sejumlah 19 responden $(73,1 \%)$. Kategori pengetahuan cukup diperoleh responden apabila mampu menjawab dengan benar sedikitnya 5 pertanyaan dari total 10 pertanyaan yang diajukan dalam penelitian ini. Untuk pengalaman masa lalu pada tabel 1 menunjukkan bahwa jumlah terbanyak adalah responden dengan risiko rendah yang memiliki self efficacy baik yaitu sejumlah 18 responden $(78,3 \%)$. Kategori risiko rendah diperoleh apabila responden menjawab "tidak" pada 11 pernyataan yang diajukan dalam penelitian ini. Untuk kemampuan bertindak (skill) pada tabel 1 menunjukkan bahwa jumlah terbanyak adalah responden dengan skill baik yang memiliki self efficacy baik yaitu sejumlah 25 responden $(83,3 \%)$. Kategori skill baik diperoleh apabila responden menjawab "bisa" pada 4 pernyataan yang diajukan dalam penelitian ini.

Hasil penelitian menurut variabel Vicarious Experience dapat dilihat pada tabel 2.

Tabel 2 menunjukkan bahwa jumlah terbanyak adalah responden yang tidak memiliki pengalaman sakit kanker payudara
Tabel 2. Distribusi Frekuensi Berdasarkan Vicarious Experience dan Self Efficacy

\begin{tabular}{|c|c|c|c|c|c|}
\hline \multicolumn{6}{|c|}{ Vicarious Experience } \\
\hline \multirow{3}{*}{$\begin{array}{c}\text { Pengalaman } \\
\text { Keluarga }\end{array}$} & \multicolumn{4}{|c|}{ Self Efficacy } & \multirow{2}{*}{$\sum$} \\
\hline & \multicolumn{2}{|c|}{ Sedang } & \multicolumn{2}{|c|}{ Baik } & \\
\hline & n & $\%$ & n & $\%$ & $\mathbf{N}$ \\
\hline Tidak Ada & 7 & 24,1 & 22 & 75,9 & 29 \\
\hline Ada & 1 & 25 & 3 & 75 & 4 \\
\hline Total & 8 & 24,2 & 25 & 75,8 & 33 \\
\hline \multirow{3}{*}{$\begin{array}{c}\text { Pengalaman } \\
\text { Orang Terdekat }\end{array}$} & \multicolumn{4}{|c|}{ Self Efficacy } & \\
\hline & \multicolumn{2}{|c|}{ Sedang } & \multicolumn{2}{|c|}{ Baik } & \\
\hline & $\mathbf{n}$ & $\%$ & $\mathbf{n}$ & $\%$ & $\mathbf{N}$ \\
\hline Tidak Ada & 5 & 29,4 & 12 & 70,6 & 17 \\
\hline Ada & 3 & 18,8 & 13 & 81,3 & 16 \\
\hline Total & 8 & 24,2 & 25 & 75,8 & 33 \\
\hline
\end{tabular}

pada keluarganya dengan memiliki self efficacy yang baik yaitu sejumlah 22 responden $(75,9 \%)$. Kategori tidak ada pengalaman sakit kanker payudara pada keluarga diperoleh apabila responden menjawab "tidak" pada 3 pertanyaan yang diajukan dalam penelitian ini. Pada tabel 2 juga menunjukkan bahwa jumlah terbanyak adalah responden yang memiliki pengalaman sakit kanker payudara pada orang terdekatnya dengan memiliki self efficacy yang baik yaitu sejumlah 13 responden $(81,3 \%)$. Kategori memiliki pengalaman sakit kanker payudara pada orang terdekat, dalam hal ini adalah tetangga dan teman responden diperoleh apabila responden menjawab "ya" pada 3 pertanyaan yang diajukan dalam penelitian ini.

Hasil penelitian menurut variabel Social Persuasion dapat dilihat pada tabel 3.

Tabel 3 menunjukkan bahwa jumlah terbanyak adalah responden yang mendapatkan dukungan sosial dan memiliki self efficacy yang baik yaitu sejumlah 19 responden (76\%). Kategori mendapatkan dukungan sosial diperoleh apabila responden menjawab "pernah" pada 3 pertanyaan yang diajukan dalam penelitian ini. Pada tabel 2 juga menunjukkan bahwa jumlah terbanyak adalah responden yang mendapatkan informasi kesehatan dan memiliki self efficacy yang baik yaitu sejumlah 21 responden (75\%). Kategori mendapatkan informasi kesehatan diperoleh apabila responden menjawab "pernah" pada 
Tabel 3. Distribusi Frekuensi Berdasarkan Social Persuasion dan Self Efficacy

\begin{tabular}{|c|c|c|c|c|c|}
\hline \multicolumn{6}{|c|}{ Sosial Persuasion } \\
\hline \multirow{3}{*}{$\begin{array}{c}\text { Dukungan } \\
\text { Sosial }\end{array}$} & \multicolumn{4}{|c|}{ Self Efficacy } & \multirow{3}{*}{$\frac{\sum}{\mathbf{N}}$} \\
\hline & \multicolumn{2}{|c|}{ Sedang } & \multicolumn{2}{|c|}{ Baik } & \\
\hline & n & $\%$ & $\mathbf{n}$ & $\%$ & \\
\hline $\begin{array}{l}\text { Tidak } \\
\text { Mendapatkan }\end{array}$ & 2 & 25 & 6 & 75 & 8 \\
\hline Mendapatkan & 6 & 24 & 19 & 76 & 16 \\
\hline Total & 8 & 24,2 & 25 & 75,8 & 33 \\
\hline \multirow{3}{*}{$\begin{array}{l}\text { Informasi } \\
\text { Kesehatan }\end{array}$} & \multicolumn{4}{|c|}{ Self Efficacy } & \\
\hline & \multicolumn{2}{|c|}{ Sedang } & \multicolumn{2}{|c|}{ Baik } & \\
\hline & $\mathbf{n}$ & $\%$ & $\mathrm{n}$ & $\%$ & $\mathbf{N}$ \\
\hline $\begin{array}{l}\text { Tidak } \\
\text { Mendapatkan }\end{array}$ & 1 & 20 & 4 & 80 & 5 \\
\hline Mendapatkan & 7 & 25 & 21 & 75 & 28 \\
\hline Total & 8 & 24,2 & 25 & 75,8 & 33 \\
\hline
\end{tabular}

3 pertanyaan yang diajukan dalam penelitian ini.

Hasil penelitian menurut variabel Physiological and Emotional States dapat dilihat pada tabel 4 .

Tabel 4 menunjukkan bahwa jumlah terbanyak adalah responden dengan penghasilan keluarga cukup dan memiliki self efficacy yang baik yaitu sejumlah 16

Tabel 4. Distribusi Frekuensi Berdasarkan Physiological and Emotional States dan Self Efficacy

\begin{tabular}{|c|c|c|c|c|c|}
\hline \multicolumn{6}{|c|}{ Physiological and Emotional States } \\
\hline \multirow{3}{*}{$\begin{array}{l}\text { Penghasilan } \\
\text { Keluarga }\end{array}$} & \multicolumn{4}{|c|}{ Self Efficacy } & \multirow{2}{*}{$\sum$} \\
\hline & \multicolumn{2}{|c|}{ Sedang } & \multicolumn{2}{|c|}{ Baik } & \\
\hline & $\mathbf{n}$ & $\%$ & $\mathbf{n}$ & $\%$ & $\mathbf{N}$ \\
\hline Rendah & 3 & 27 & 18 & 73 & 11 \\
\hline Cukup & 5 & 23,8 & 16 & 76,2 & 21 \\
\hline Tinggi & 0 & 0 & 1 & 100 & 1 \\
\hline Total & 8 & 24,2 & 25 & 75,8 & 33 \\
\hline \multirow{3}{*}{$\begin{array}{c}\text { Suasana } \\
\text { Hati }\end{array}$} & \multicolumn{4}{|c|}{ Self Efficacy } & $\Gamma$ \\
\hline & \multicolumn{2}{|c|}{ Sedang } & \multicolumn{2}{|c|}{ Baik } & 乙 \\
\hline & $\mathbf{n}$ & $\%$ & n & $\%$ & $\mathbf{N}$ \\
\hline Mood Sedang & 2 & 66,7 & 1 & 33,3 & 3 \\
\hline Mood Baik & 6 & 20 & 24 & 80 & 30 \\
\hline Total & 8 & 24,2 & 25 & 75,8 & 33 \\
\hline \multirow{3}{*}{$\begin{array}{l}\text { Perasaan Emosi } \\
\text { yang Negatif }\end{array}$} & \multicolumn{4}{|c|}{ Self Efficacy } & $\Gamma$ \\
\hline & \multicolumn{2}{|c|}{ Sedang } & \multicolumn{2}{|c|}{ Baik } & 2 \\
\hline & $\mathbf{n}$ & $\%$ & $\mathbf{n}$ & $\%$ & $\mathbf{N}$ \\
\hline Emosi Sedang & 2 & 100 & 0 & 0 & 2 \\
\hline Emosi Baik & 6 & 19,4 & 25 & 80,6 & 31 \\
\hline Total & 8 & 24,2 & 25 & 75,8 & 33 \\
\hline
\end{tabular}

responden $(76,2 \%)$. Kategori penghasilan cukup diperoleh apabila responden memiliki penghasilan keluarga sebesar Rp. 2.000.001,- sampai Rp. 4.000.000,tiap bulannya. Untuk suasana hati (mood) diketahui bahwa jumlah terbanyak adalah responden yang memiliki mood baik dan memiliki self efficacy yang baik yaitu sejumlah 24 responden (80\%). Kategori mood baik diperoleh apabila mayoritas responden menjawab "sangat setuju (SS)" pada total 3 pernyataan favorable yang diajukan dalam penelitian ini. Selanjutnya untuk perasaan emosi yang negatif pada tabel 4 diketahui bahwa jumlah terbanyak adalah responden yang memiliki emosi baik dan memiliki self efficacy yang baik yaitu sejumlah 25 responden (80,6\%). Kategori emosi baik diperoleh apabila mayoritas responden menjawab "sangat tidak setuju (STS)" pada total 7 pernyataan unfavorable yang diajukan dalam penelitian ini.

Hasil penelitian menurut variabel Self Efficacy dapat dilihat pada tabel 5 .

Pada tabel 5 menunjukkan bahwa jumlah terbanyak adalah responden yang memiliki self efficacy baik dan memiliki perilaku SADARI yang baik yaitu sejumlah 18 responden (72\%). Kategori self efficacy baik diperoleh apabila mayoritas responden menjawab "sangat setuju (SS)" pada pernyataan favorable dan menjawab "sangat tidak setuju (STS)" pada pernyataan unfavorable yang diajukan dalam penelitian ini sebanyak 7 item pernyataan.

Tabel 5. Distribusi Frekuensi Berdasarkan Self Efficacy dan Perilaku SADARI

\begin{tabular}{lccccr}
\hline \multirow{2}{*}{$\begin{array}{c}\text { Self } \\
\text { Efficacy }\end{array}$} & \multicolumn{4}{c}{ Perilaku SADARI } & \multirow{2}{*}{$\sum$} \\
\cline { 2 - 5 } & \multicolumn{2}{c}{ Sedang } & \multicolumn{2}{c}{ Baik } & \\
\cline { 2 - 5 } & $\mathbf{n}$ & $\mathbf{\%}$ & $\mathbf{n}$ & $\mathbf{\%}$ & $\mathbf{N}$ \\
\hline Sedang & 3 & 37,5 & 5 & 62,5 & 8 \\
Baik & 7 & 28 & 18 & 72 & 25 \\
\hline Total & $\mathbf{1 0}$ & $\mathbf{3 0 , 3}$ & $\mathbf{2 3}$ & $\mathbf{6 9 , 7}$ & $\mathbf{3 3}$ \\
\hline
\end{tabular}

\section{PEMBAHASAN}

Performance accomplishments terdiri dari pengetahuan, pengalaman masa lalu dan kemampuan untuk bertindak (skill). Hasil penelitian berdasarkan tabel 1 menunjukkan bahwa tingkat pengetahuan yang cukup 
berhubungan dengan self efficacy yang baik. Hal ini sesuai dengan hasil penelitian Setiawan (2012) yang menyatakan bahwa ada hubungan yang signifikan antara pengetahuan responden dengan tindakan pencegahan kanker payudara. Hal yang sama juga terjadi pada penelitian Mardhiani (2003) yang menyebutkan adanya hubungan antara tingkat pengetahuan tentang kanker payudara dengan pemeriksaan payudara sendiri pada wanita.

Pengetahuan yang dimiliki oleh perempuan akan berpengaruh terhadap self efficacy nya dalam melakukan periksa payudara sendiri. Notoatmodjo (2007) mengemukakan bahwa pengetahuan terjadi setelah orang melakukan pengindraan terhadap suatu objek tertentu. Pengindraan terjadi melalui panca indera manusia, yakni indera penglihatan, pendengaran, penciuman, rasa dan raba. Pengindraan yang baik akan meningkatkan pemahaman terhadap suatu objek atau informasi.

Hasil penelitian berdasarkan tabel 1 menunjukkan bahwa responden yang memiliki risiko rendah terhadap kanker payudara memiliki self efficacy yang baik dalam melakukan SADARI. Hal ini sesuai dengan penelitian Masyitah (2013) yang menyatakan bahwa terdapat $41,9 \%$ responden dengan persepsi kurang rentan terhadap kanker payudara namun tetap melakukan SADARI secara rutin. Selanjutnya berdasarkan tabel 1 menunjukkan bahwa responden yang memiliki skill baik memiliki self efficacy yang baik pula dalam melakukan SADARI. Hal ini sesuai dengan penelitian Olfah (2014) yang menyatakan bahwa ada pengaruh pelatihan terhadap perilaku SADARI. Adanya hubungan antara skill dan self efficacy perempuan tidak terlepas dari rasa percaya diri yang dimiliki oleh perempuan dalam melakukan SADARI. Schultz (2005) mendefinisikan bahwa self efficacy merupakan keyakinan atau kepercayaan individu terhadap kemampuan yang dimilikinya dalam melaksanakan dan menyelesaikan tugas-tugas yang ia hadapi, sehingga mampu mengatasi rintangan dan mencapai tujuan yang diharapkannya.

Hasil wawancara pada Bidan pemegang Program Kesehatan Reproduksi didapatkan hasil bahwa health education tentang SADARI sudah diberikan kepada setiap klien yang datang pada Poli Kesehatan Reproduksi. Health education yang diberikan berupa manfaat melakukan SADARI serta cara melakukan SADARI dengan baik dan benar. Diharapkan upaya pemberian health education dari tenaga kesehatan ini mampu menjadi bekal agar klien mampu melakukan SADARI dengan benar, rutin dan mandiri.

Vicarious experience terdiri dari pengalaman keluarga dan pengalaman orang terdekat. Hasil penelitian berdasarkan tabel 2 menunjukkan bahwa responden yang tidak memiliki pengalaman sakit kanker payudara pada keluarganya memiliki self efficacy yang baik untuk melakukan SADARI. Hal ini sesuai dengan teori Notoatmodjo (2010) yang menyatakan bahwa sikap adalah suatu respons tertutup seseorang terhadap stimulus atau objek tertentu yang sudah melibatkan faktor pendapat dan emosi yang bersangkutan. Sikap yang dimiliki oleh seorang perempuan adalah suatu kesatuan dari berbagai komponen yang bersifat evaluasi. Secara umum sikap dapat dirumuskan sebagai kecenderungan untuk berespons secara positif atau negatif terhadap orang, objek atau situasi tertentu. Responden yang tidak memiliki pengalaman sakit kanker payudara pada keluarganya cenderung memiliki self efficacy yang baik dalam melakukan SADARI. Karena ia telah melakukan evaluasi sebagai respons terhadap suatu objek yang ditunjukkan dengan sikap positif, dalam hal ini adalah periksa payudara sendiri.

Selanjutnya berdasarkan tabel 2 menunjukkan bahwa responden yang memiliki pengalaman sakit kanker payudara pada orang terdekatnya memiliki self efficacy yang baik dalam melakukan SADARI. Sesuai dengan penelitian Masyitah (2013) didapatkan hasil bahwa $55,1 \%$ responden yang memiliki persepsi serius tentang penyakit kanker payudara maka akan melakukan SADARI. Hal ini dilakukan karena responden memiliki contoh nyata dari akibat penyakit kanker payudara terhadap orang-orang terdekat yang berada disekitarnya, sehingga responden akan melakukan SADARI dengan sukarela karena 
ia takut dengan konsekuensi yang bisa ia terima apabila tidak melalukan deteksi dini pada kanker payudara.

Bandura (1987) menyatakan bahwa ekspektasi efficacy dapat berubah setelah mengamati orang lain dan melihat konsekuensi positif dan negatif dari perilaku orang itu baginya. Ekspektasi efficacy yang dibentuk melalui modelling akan mempengaruhi keyakinan efficacy nya.

Social persuasion terdiri dari dukungan sosial dan informasi kesehatan. Hasil penelitian berdasarkan tabel 3 menunjukkan bahwa responden yang mendapatkan dukungan sosial maka akan memiliki self efficacy yang baik. Hal ini sesuai dengan penelitian Basri (2011) yang menyatakan bahwa ada hubungan motivasi tentang SADARI dengan tindakan SADARI. Motivasi yang didapat berasal dari dukungan sosial maupun buku-buku yang dibaca sehingga responden tertarik untuk melaksanakan SADARI. Hasil yang sama juga terjadi pada penelitian Fatayati (2015) yang menyatakan bahwa ada hubungan dukungan sosial dengan kebiasaan SADARI. Frey (1988) mengungkapkan bahwa dukungan sosial merupakan hubungan interpersonal dalam bentuk interaksi antara dua orang atau lebih menggunakan komunikasi verbal maupun non verbal yang dikarakteristikkan dengan nilai, untuk bertukar informasi, barang maupun tersedianya bantuan. Berdasarkan tabel 3 menunjukkan bahwa responden yang mendapatkan informasi kesehatan maka akan memiliki self efficacy yang baik. Hal ini sesuai dengan penelitian Deniar (2013) yang menyatakan bahwa sikap perempuan tergolong negatif tentang pencegahan kanker payudara sebelum diberikan pendidikan kesehatan tentang kanker payudara dan pencegahannya. Namun setelah diberikan pendidikan kesehatan, sikap perempuan berubah menjadi sikap positif dan mau melakukan tindakan pencegahan kanker payudara. Dalam penelitian Hokum (2003) juga menyebutkan bahwa ada pengaruh pemberian penyuluhan tentang pemeriksaan kanker payudara terhadap keikutsertaan deteksi dini kanker payudara pada wanita usia 30-50 tahun.
Notoatmodjo (2003) menyatakan bahwa pengaruh penyuluhan terhadap perubahan atau peningkatan pengetahuan tersebut sesuai dengan tujuan jangka pendek dari sebuah pendidikan kesehatan. Selain itu dalam suatu penyuluhan ada tahap yang disebut dengan tahap edukasi. Tahap ini merupakan kelanjutan dari tahap sensitisasi yang mempunyai tujuan untuk meningkatkan pengetahuan, mengubah sikap serta mengarahkan pada perilaku yang diinginkan. Hasil wawancara yang dilakukan pada responden didapatkan informasi bahwa para responden telah mendapatkan cukup informasi tentang SADARI melalui tenaga kesehatan yang ada di Puskesmas Tembok Dukuh Kota Surabaya serta melalui televisi seperti iklan kesehatan dari Kementerian Kesehatan Republik Indonesia. Beberapa responden juga sudah mendapatkan dukungan sosial terutama dari keluarga. Karena informasi tentang SADARI juga dilakukan oleh pihak Puskesmas Tembok Dukuh Kota Surabaya di kampung-kampung yang berada pada wilayah kerja Puskesmas Tembok Dukuh Kota Surabaya dalam berbagai acara seperti PKK dan berbagai acara yang dilaksanakan oleh warga setempat. Sehingga para warga yang belum pernah datang pada Poli Kesehatan Reproduksi juga berkesempatan untuk mendengarkan informasi terkait SADARI.

Physiological and emotional states terdiri dari ekonomi, suasana hati (mood), dan perasaan emosi yang negatif. Hasil penelitian berdasarkan tabel 4 menunjukkan bahwa jumlah terbanyak responden dengan penghasilan keluarga cukup memiliki self efficacy yang baik. Hal ini sesuai dengan penelitian Desanti (2010) yang menyatakan bahwa responden yang paling sering mengatakan pernah melakukan SADARI adalah responden dengan penghasilan keluarga yang cukup yaitu sebanyak 153 responden $(55,6 \%)$, sementara responden yang memiliki penghasilan keluarga rendah hanya 48 responden (44\%) yang menyatakan pernah melakukan SADARI.

Berdasarkan tabel 4 menunjukkan bahwa responden yang memiliki mood baik maka akan memiliki self efficacy yang 
baik. Hal ini sesuai dengan hasil penelitian Sari (2013) yang menyatakan bahwa ada hubungan yang signifikan antara suasana hati terhadap efikasi diri wanita dalam melakukan deteksi dini kanker payudara. Notoatmodjo (2007) menyatakan bahwa suatu sikap optimis terwujud dalam suatu tindakan (overt behavior). Untuk mewujudkan sikap menjadi suatu perbuatan nyata diperlukan faktor pendukung atau suatu kondisi yang memungkinkan, antara lain fasilitas dan orang-orang terdekat. Berdasarkan tabel 4 menunjukkan bahwa responden yang memiliki emosi baik maka akan memiliki self efficacy yang baik. Hal ini sesuai dengan teori Bandura (1987) yang menyatakan bahwa suatu keadaan atau fisiologis dan afektif dapat berpengaruh terhadap self efficacy. Seseorang yang sedang tegang dan cemas, keadaan fisiologis atau tingkat emosi nya dapat berpengaruh negatif terhadap ekspektasi efficacy-nya. Begitu pula sebaliknya apabila seseorang yang sedang dalam keadaan fisiologis atau tingkat emosi yang baik, maka dapat berpengaruh positif terhadap ekspektasi efficacy-nya. Keadaan perasaan (mood) mempengaruhi penilaian tentang self efficacy. Perasaan yang positif akan meningkatkan keyakinan efficacy.

Hasil penelitian berdasarkan tabel 5 menunjukkan bahwa responden yang memiliki self efficacy baik dan memiliki perilaku SADARI yang baik. Baranowski et al. Dalam Glanz et al. (2008) menyatakan bahwa perilaku digambarkan dalam sesuatu yang bersifat dinamis, yaitu tergantung pada aspek lingkungan dan individu yang saling mempengaruhi satu sama lain secara serempak. Maka setiap perubahan dari masing-masing komponen perilaku, lingkungan dan individu akan menentukan dan memberikan implikasi satu sama lain (reciprocal determinism).

Berdasarkan hasil penelitian di lapangan didapatkan hasil bahwa para responden sudah memiliki beberapa komponen dari dalam dan dari luar individu untuk yang mendukung adanya suatu perilaku periksa payudara sendiri. Pada penelitian Yang (2010) di Taiwan menyatakan bahwa rasa keamanan diri menjadi faktor penting untuk memutuskan apakah ia akan melakukan SADARI atau tidak. Rasa terhadap kecukupan, efisiensi dan kemampuan dalam mengatasi kehidupan inilah yang disebut dengan self efficacy (Schultz, 2005).

Perilaku periksa payudara sendiri sangat penting dilakukan oleh para perempuan. Varney (2004) menyatakan bahwa insiden kanker payudara meningkat seiring dengan pertambahan usia perempuan. Maka kesadaran akan pentingnya perilaku SADARI sebagai upaya deteksi dini kanker payudara perlu ditingkatkan pula. Hal ini juga sesuai dengan rekomendasi dari American Cancer Society yang menganjurkan bagi wanita yang mulai memasuki usia 20 tahun ke atas untuk melakukan periksa payudara sendiri dengan tepat dan sesuai dengan pedoman tekniknya (Smith, 2003).

\section{KESIMPULAN}

Berdasarkan analisis data dan pembahasan maka didapatkan kesimpulan bahwa pada performance accomplishments mayoritas responden dengan pengetahuan cukup, risiko rendah dan skill baik memiliki self efficacy yang baik. Pada vicarious experience mayoritas responden yang tidak memiliki pengalaman sakit kanker payudara pada keluarganya memiliki self efficacy yang baik. Dan mayoritas responden yang memiliki pengalaman sakit kanker payudara pada orang terdekatnya memiliki self efficacy yang baik. Pada social persuasion mayoritas responden yang mendapatkan dukungan sosial dan informasi kesehatan memiliki self efficacy yang baik. Pada physiological and emotional states mayoritas responden dengan penghasilan keluarga cukup, mood baik dan emosi baik memiliki self efficacy yang baik. Mayoritas responden dengan self efficacy baik memiliki perilaku SADARI yang baik pula.

\section{SARAN}

Diharapkan upaya promosi kesehatan terkait kesehatan reproduksi tidak hanya seputar diseminasi informasi saja, melainkan bisa diberikan dalam metode lain agar responden lebih mudah dalam menerima materi. Seperti kuis ular tangga, pemutaran film tentang kanker payudara dan SADARI. 
Hal ini diharapkan mampu menarik minat pada perempuan yang belum mengikuti kegiatan deteksi dini kanker payudara. Hal yang dapat dilakukan oleh tenaga kesehatan untuk meningkatkan angka cakupan SADARI bisa dengan meningkatkan self efficacy para perempuan serta memberikan nilai-nilai motivasi kepada responden agar lebih peduli terhadap kesehatan reproduksi nya.

\section{DAFTAR PUSTAKA}

Azwar, S. 2000. Sikap Manusia: Teori dan Pengukurannya (Edisi kedua). Yogyakarta: Pustaka Belajar.

Bandura, A. 1987. Social Foundation of Thought and Action: A Social Cognitive Theory. Englewood Cliff, NJ: Prentice Hall.

Bandura, A. 1997. SelfEfficacy: The Exercise of Control. New York: Freeman and Company.

Basri, A.H. 2011. Hubungan Pengetahuan, Sikap dan Motivasi Terhadap Tindakan Pemeriksaan Payudara Sendiri pada Mahasiswa FKM UNHAS. Makassar: Skripsi FKM Universitas Hasanuddin.

Chen, R. 2012. Solusi Cerdas mencegah dan Mengobati Kanker. Jakarta: PT. Agro Media Pustaka. Data Kanker Indonesia Tahun 2010. Badan Registrasi Kanker Perhimpunan Dokter Spesialis Patologi Indonesia (IAPI) dan Yayasan Kanker Indonesia (YKI).

Deniar, O.R. 2013. Pengaruh Pendidikan Kesehatan Tentang Pencegahan Kanker Payudara Terhadap Tingkat Pengetahuan dan Sikap pada Wanita Usia Produktif di Desa Sumur Musuk Boyolali.

Departemen Kesehatan Republik Indonesia. 2009. Program-Program Kesehatan. Jakarta: Depkes RI.

Desanti, Ophi Indria., Sunarsih, Supriyati. 2010. Perception of Women with Risk of Breast Cancer About Breast Self Examination at Semarang City, Central Java. Berita Kedokteran Masyarakat. Vol. 26, No. 3, September 2010. [Jurnal Online diakses pada tanggal 9 Januari 2017].
Dinas Kesehatan Kota Surabaya. 2015. Profil Kesehatan Tahun 2015. Surabaya: Dinkes Kota Surabaya.

Fatayati, A. 2015. Hubungan Dukungan Sosial Terhadap Perilaku Pemeriksaan Payudara Sendiri (SADARI) di Wilayah Kerja Puskesmas Manyaran Kabupaten Wonogiri. Surakarta: Tesis Universitas Sebelas Maret.

Frey, M.A. 1988. Social Support and Health: A Theoretical Formulation Derivat From King's Conceptual Framework. Amerika Serikat: University of Michigan.

Ghufron, M.N., \& Rini R.S. 2010. TeoriTeori Psikologi. Yogyakarta: Ar-Ruzz Media.

Glandz, Karen. 2008. Health Behavior and Health Education (Theory, Research, and Practice 4 $^{\text {th }}$ Edition. U.S.A: Jossey Bass.

Hadi, S. 2000. Methodology Research (Jilid 1-4). Yogyakarta: Yayasan Penerbitan Fakultas psikologi Universitas Gadjah Mada.

Hokum. 2013. Penatalaksanaan Payudara Terkini. Jakarta: Populer Obor. International Agency for Research on Cancer (IARC) / WHO. 2012. GLOBOCAN 2012: Estimated Cancer Incidence, Mortality, and Prevalence worldwide in 2012.

Kementerian Kesehatan RI. 2013. Riset Kesehatan Dasar (Riskesdas). Jakarta: Badan Litbang Kemenkes RI.

Kementerian Kesehatan RI. 2014. Buletin Jendela, Data dan Informasi Kesehatan. Jakarta: Kementerian Kesehatan RI.

Mardhiani, Luwia. 2003. Problematik dan Perawatan Payudara. Jakarta: Kawan Pustaka.

Masyitah, Siti. 2013. Gambaran Praktik Pemeriksaan Payudara Sendiri (SADARI) pada Mahasiswi S1 Reguler Universitas Indonesia Tahun 2013 Menggunakan Pendekatan Health Belief Model. Depok: Skripsi FKM Universitas Indonesia.

Noor, Juliansyah. 2011. Metodologi Penelitian. Jakarta: Kencana Prenada Media.

Notoatmodjo, S. 2003. Pendidikan dan Perilaku Kesehatan. Jakarta: Rineka Cipta. 
Notoatmodjo, S. 2007. Pendidikan dan Perilaku Kesehatan. Jakarta: Rineka Cipta.

Notoatmodjo, S. 2010. Pendidikan dan Perilaku Kesehatan. Jakarta: Rineka Cipta.

Notoadmodjo, S. 2010. Metodologi Penelitian Kesehatan. Jakarta: Rineka Cipta.

Nursalam. 2003. Konsep \& Penerapan Metodologi Penelitian Ilmu Keperawatan. Jakarta, Salemba Medika.

Olfah, Yustiana. 2014. Pengaruh Pelatihan Menggunakan Modul Tentang Kanker Payudara Terhadap Pengetahuan, Minat dan Perilaku dalam Melakukan Pemeriksaan Payudara Sendiri (SADARI) pada Wanita Usia 20-40 Tahun di Propinsi Daerah Istimewa Yogyakarta (DIY). Yogyakarta: Prosiding Konferensi Nasional II PPNI Jawa Tengah.

Purwoastuti, Endang. 2008. Kanker Payudara. Yogyakarta: Kanisius.

Putri, Naura. 2009. Deteksi Dini Kanker Payudara. Yogyakarta: Aura Media.

Rasjidi, Imam. 2009. Deteksi Dini Kanker Payudara. Jakarta: CV. Sagung Seto.
Sari, T.M. 2013. Faktor-Faktor yang Berhubungan dengan Perilaku Deteksi Dini Kanker Payudara pada Wanita Pasangan Usia Subur di Desa Dawung Kebakkramat Karanganyar. Surakarta: Skripsi Universitas Muhammadiyah Surakarta.

Schultz, D. \& Schultz, E.S. 2005. Theories of Personality $\left(8^{\text {th }} e d\right)$. Wodsworth.

Setiawan, F.S. 2012. Hubungan Pengetahuan dan Deteksi Dini (SADARI) dengan Keterlambatan Penderita Kanker Payudara Melakukan Pemeriksaan di RSUD. Kraton Kabupaten Pekalongan. Pekajangan: Skripsi STIKES Muhammadiyah Pekajangan.

Setiati, E. 2009. Waspadai 4 Kanker Ganas Pembunuh Wanita World Health Organization. 2013. Prevention. Cancer control: Knowledge into action: WHO guide for effective programmes: module 2). Geneva: World Health Organization.

Yang, R-J. 2010. Motivations and Reason for Women Attending a Breast Self Examination Training Program: A Qualitative Study. Taiwan: BMC Womens Health. 